American J. of Engineering and Applied Sciences 3 (3): 529-533, 2010

ISSN 1941-7020

(C) 2010 Science Publications

\title{
Estimation of Non-Residential Building Energy Consumption
}

\author{
${ }^{1}$ Yongzhi Gao, ${ }^{1}$ Weijun Gao, ${ }^{1} \mathrm{Ji}$ Xuan and ${ }^{2}$ Yutaka Tonooka \\ ${ }^{1}$ Department of Architecture, University of Kitakyushu, Japan \\ ${ }^{2}$ Department of Social Environmental Design, Saitama University, Japan
}

\begin{abstract}
Problem statement: China's energy consumption is increasing with a high-speed in recent years. Especially since building energy consumption caught pubic eyes and became a crucial problem of society, it forced the public to make estimation in order to reduce energy consumption efficiently. However, it is very difficult to analyze a non-residential building accurately due to China's statistical collection system and the lack of national surveys. Approach: This study introduced a methodology of estimating various energy consumption factors by building types, energy end-use (electric power, space heating, space cooling and hot water) in each province. The unit energy consumption factors were determined based on sample cities' data and modification by using software analysis. Take 2006 year for example, the estimation method was introduced. Results: The non-residential building energy consumption in China in 2006 year was estimated by the method above mentioned. Through the result of analysis, we found out that energy consumption of space heating, space cooling and hot water were greatly affected by space Heating Degree Day (HDD), space Cooling Degree Day (CDD) and regional consumer spending per person (Op-c). Conclusion: A series of formulas were obtained. So by using the formulas we can not only estimate the energy consumption now, but also the energy consumption in future. However, this is the first step of our research. It might be hoped that the further surveys and research on energy consumption of China can be done to promote our research result.
\end{abstract}

Key words: Non-residential building, energy consumption, estimation, China

\section{INTRODUCTION}

China's building energy consumption increases rapidly in resent years. It seems that a large amount of the greenhouse gas which due to the rapid increase of the energy consumption is the main cause of climate change. In order to reduce China's non-residential building energy consumption, it is necessary to study on this research.

There are several studies have been researched on energy consumption in China. Zhou (2008) evaluated the impact of GDP grows on energy consumption in China's commercial buildings. Zhao (2009) also did a study on energy consumption of a commercial building in TianJin in China. Chen (2008) provided a method to investigate national energy consumption in the residential building sector of China. Tonooka (2008); Tonooka et al. (2004; 2006) researched on China's energy consumption and focused on China's energy and environment in rural housing and energy consumption in rural household. We also studied the Centre for Energy Saving Studies of Tsinghua University (2008). However, in all these researches, a general method for estimating non-residential building energy consumption in China has not yet been developed.
In order to understand the energy consumption in non-residential building, we have to get the data first. However, it is very difficult to survey the energy consumption of non-residential building in a wide range of China. Therefore, the general method is to classify provinces by using cluster analysis and then propose an estimation method based on the survey of sample cities in each classification.

\section{MATERIALS AND METHODS}

Non-residential building is categorized as shown in Fig. 1, which called "public building in china. In detail, non-residential buildings in China can be divided into 8 types, such as office, commercial, hotel and restaurant, education facility, culture facility, hospital, research centre and others. In order to estimate the energy consumption, there must be a clear construction of the total floor area and the unit energy consumption, which is shown in chat (Fig. 2).

According to China statistical yearbook (National Bureau of Statistics of China, 2008; National Bureau of Statistics of China, 1998) and other literature, we can get the total floor area of non-residential building sector

Corresponding Author: Yongzhi Gao, Department of Architecture, University of Kitakyushu, Japan 
in China. Figure 3 shows the total floor area by building types in each province. Due to the lack of survey data, the total floor area composition ratio could not be done accurately by building types. Therefore, the Japanese total floor area composition ratio by building types is used here as reference. Next we will focus on the calculation of unit energy consumption.

The space Heating Degree Day (HDD), space Cooling Degree Day (CDD) and economical indicators $\left(\varepsilon_{1} \sim \varepsilon_{4}\right)$ in each province of China are selected and shown as following:

- Regional Gross domestic product per head $\left(\mathrm{GDP}_{\mathrm{p}-\mathrm{c}}\right) \varepsilon_{1}$

- $\quad$ Regional income per person (Ip-c) $\varepsilon_{2}$

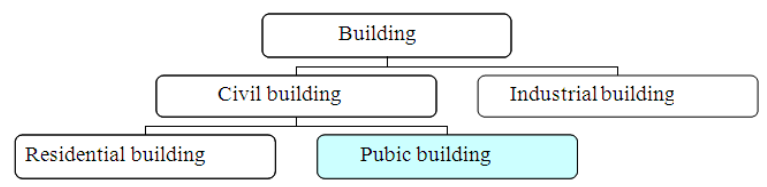

Fig. 1: Building classification in China

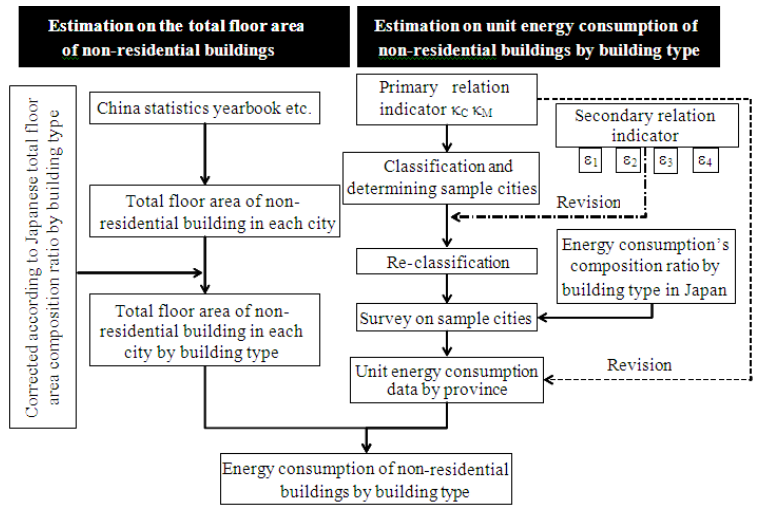

Fig. 2: Non-residential building energy consumption estimation procedure flow

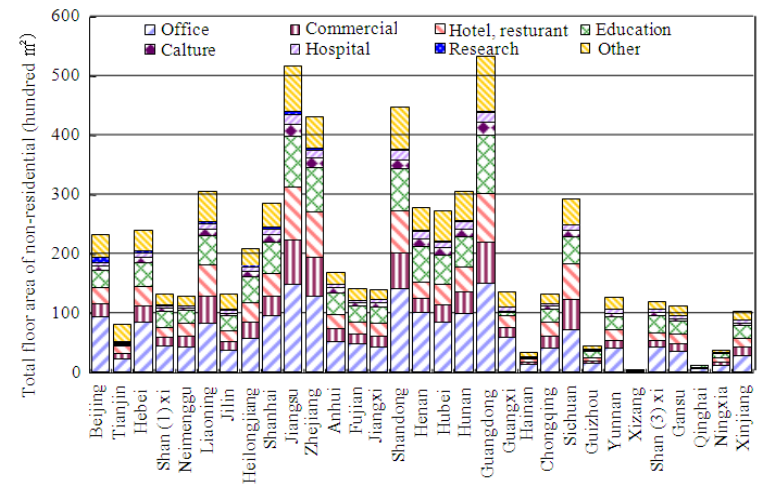

Fig. 3: Total floor area of non-residential building in each province
- $\quad$ Regional consumer spending per person (Op-c) $\varepsilon_{3}$

- Regional energy consumption per person (Ep-c) $\varepsilon_{4}$

- Regional space Heating Degree Day (HDD) $\kappa_{\mathrm{H}}$

- Regional space Cooling Degree Day $(\mathrm{CDD}) \kappa_{\mathrm{C}}$

Firstly, basing on HDD, CDD (DD), which are considered as the primary indicators of energy consumption, 31 provinces are divided into 5 classes (Area I, II, III, IV and V). The result is shown as Fig. 4.

Secondly, classification of the whole country is made one more time by the economical indicators basing on the result above. (Fig. 5 and 6)

We surveys 300 non-residential buildings of five sample cities of five areas in Table 1. They are Beijing, Shanghai, Guangdong, Jilin and Xian.

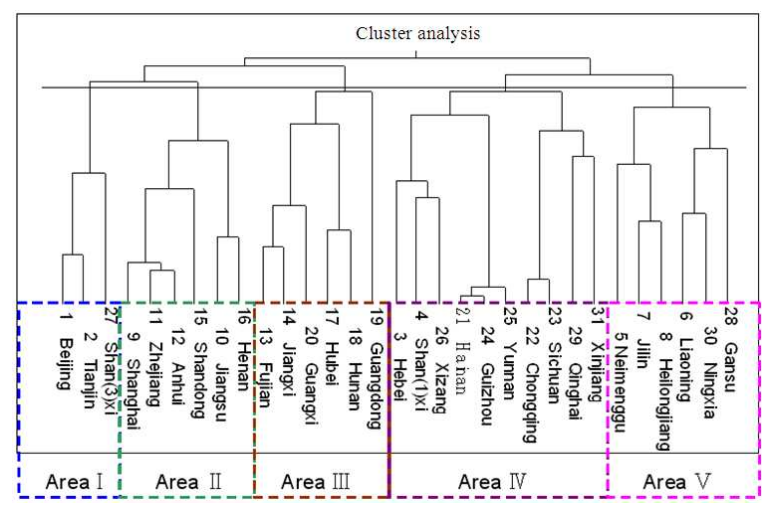

Fig. 4: Classification according to HDD and CDD

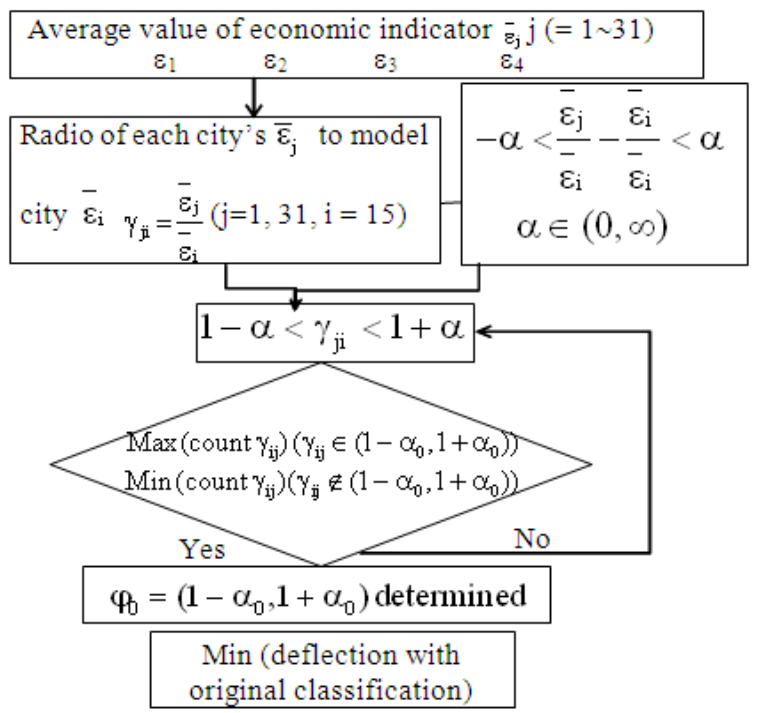

Fig. 5: Classification according to economical indicators flow 
Am. J. Engg. \& Applied Sci., 3 (3): 529-533, 2010

Table 1: Final result of classification according to economical indicators and DD

\begin{tabular}{|c|c|c|c|c|c|c|c|c|}
\hline Variable & Classification & Province/city & & & & & & \\
\hline $\begin{array}{l}\text { Regional gross } \\
\text { Domestic product per } \\
\text { head (GDPp-c) }\end{array}$ & Area I & Beijing & & Tianjin & & & & \\
\hline $\begin{array}{l}\text { Regional income per } \\
\text { person (Ip-c) }\end{array}$ & Area II & $\begin{array}{l}\text { Shanghai } \\
\text { Hunan }\end{array}$ & $\begin{array}{l}\text { Zhejiang } \\
\text { Hubei }\end{array}$ & Shandong & Jiangsu & Chongqing & Xinjiang & \\
\hline $\begin{array}{l}\text { Regional consumer } \\
\text { spending per person } \\
\text { (Op-c) }\end{array}$ & Area III & Guangdong & Fujian & Yunnan & Guizhou & Hainan & & \\
\hline $\begin{array}{l}\text { Regional energy } \\
\text { consumption per } \\
\text { person (Ep-c) }\end{array}$ & Area IV & Hebei & Shan (1) xi & Xizang & Neimenggu & Jilin & Heilongjiang & Liaoning \\
\hline $\begin{array}{l}\text { HDD } \\
\text { CDD }\end{array}$ & Area V & Gansu & $\begin{array}{l}\text { Ningxia } \\
\text { Anhui }\end{array}$ & $\begin{array}{l}\text { Qinghai } \\
\text { Guangxi }\end{array}$ & Sichuan & Jiangxi & Shan (3) xi & Henan \\
\hline
\end{tabular}

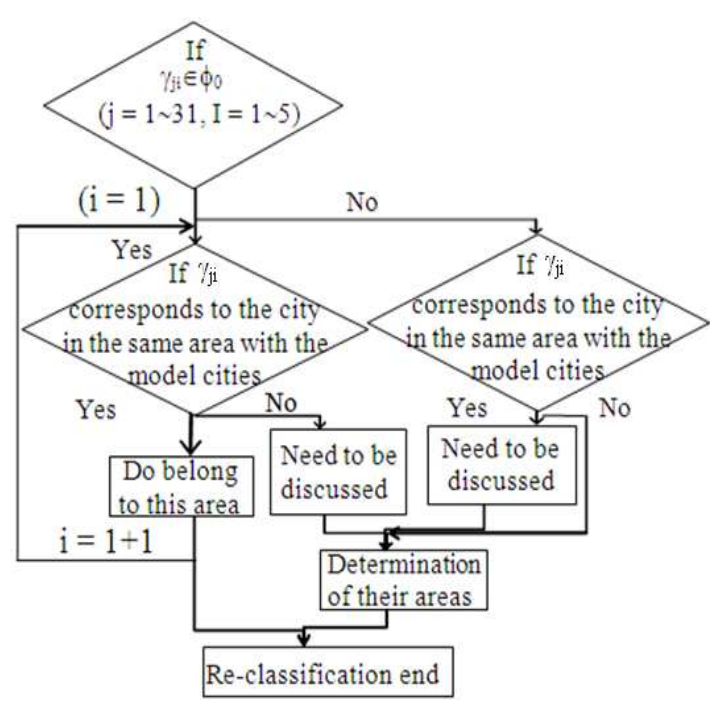

Fig. 6: Classification according to economical indicators flow 2

Unit energy consumption in each province is estimated by sample city's unit energy consumption and the result of classification and DD value. In order to find out energy the correlation between these factors and energy consumption by building types, multiple regression analysis has been done.

Multiple regression analysis of the Excel multivariate analysis is run separately under the condition that assume these factors $\left(\varepsilon_{1}, \varepsilon_{2}, \varepsilon_{2}, \varepsilon_{4}, \kappa_{\mathrm{H}}, \kappa_{\mathrm{C}}\right)$ as dependent variables and unit energy consumption (space heating, space cooling, hot water, electric power) as functions. Then the factor that has a high correlation with the unit energy consumption can be discovered through the result. However, non-residential building can be divided into 8 parts by building types as office building, followed by commercial building, hotel and restaurant, education facility, culture, hospital and others. Meanwhile, Energy consumption can be divided into 4 parts by energy types as space heating, space cooling, hot water and electric power. Owning to above reasons, the multiple regression analyses will be $4 \times 8=32$ times. Next, taking office building as an example, analysis result of multiple regression analysis will be given in coming sector.

\section{RESULTS}

Japanese energy consumption composition ratio by building types is applied here as reference for the same reason with total floor area by building types. And energy consumption of Non-residential building by building types in each province can be estimated (Fig. 7). Energy consumption in developed provinces or cities is higher than others. For example, as a developed province, Gangdong's energy consumption is higher than other provinces. Even if Beijing and Shanghai are cities, their energy consumption is very high because they are very developed cities.

The result of multiple regression analysis for energy consumption of space heating is shown as Fig. 8. It is clear that the correlation coefficient is 0.927 . And the standard error of HDD is the largest one in 5 indicators. Even the standard error of GDPp-c is also very large; it plays a role of reducing energy consumption of space heating, which could not be eliminated.

Take a look at analysis result of space cooing. (Fig. 9) the standard error of Ep-c is the largest one in 5 indicators and followed by CDD, Op-c and Ip-c. However, GDPp-c has a very weak influence on energy consumption of space cooling.

Figure 10 shows the analysis result of energy consumption of electric power. It could be found that the correlation coefficient became 0.5082. The correlation is very low compared with the analysis above. The standard error of GDPp-c is the largest one in 6 indicators. The standard error of CDD follows GDPp-c and shows a negative influence on energy consumption of electric power. 


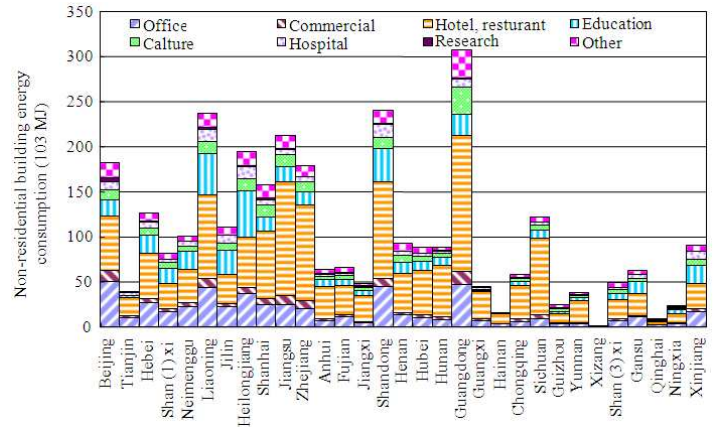

Fig. 7: Energy consumption of non-residential building by building types

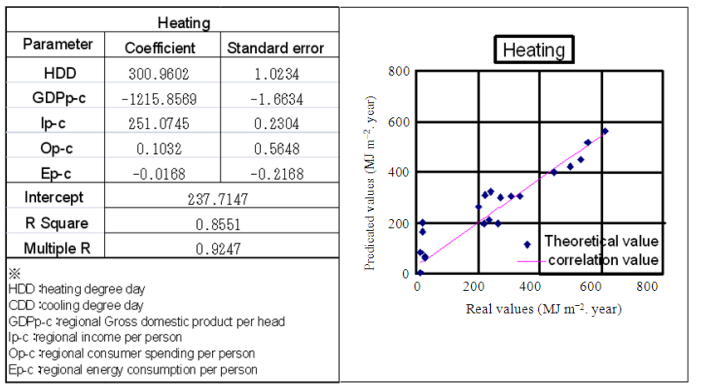

Fig. 8: Space heating-multiple regression analysis with excel

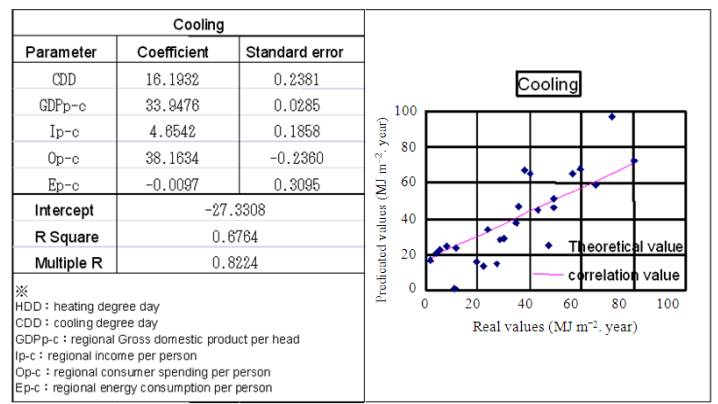

Fig. 9: Space cooling-multiple regression analysis with excel

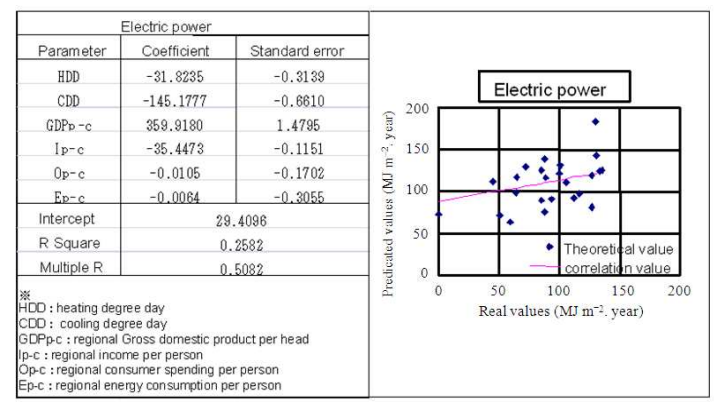

Fig. 10: Electric power-multiple regression analysis with excel

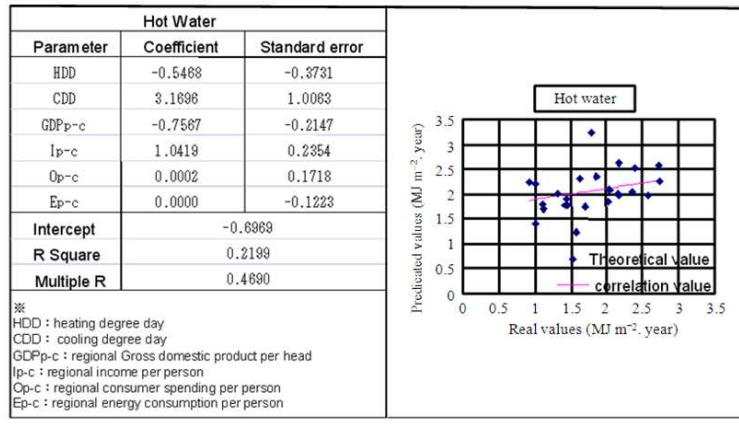

Fig. 11: Hot water-multiple regression analysis with excel

Figure 11 shows the analysis result of energy consumption of hot water. Correlation coefficient is 0.4690 . The standard error of CDD is the largest one in 6 indicators and followed by HDD.

\section{DUSCUSSION}

In conclusion, on the one hand, it is clearly revealed that energy consumption of space heating, space cooling and hot water were greatly affected by HDD and CDD, but order of other factors is irregular. On the other hand, the Figure 10 shows that energy consumption of electric power is greatly affected by GDPp-c because of the high value of standard error. The relation of energy consumption and each factor can be made into an equation by the coefficient in the chat above. So, non-residential building energy consumption of space heating of office can be estimated with formula followed:

$$
\begin{aligned}
\mathrm{Y}= & 300.9602 \times \mathrm{HDD}-1215.8569 \times \mathrm{GDPp}-\mathrm{c}+251.0745 \\
& \times \mathrm{Ip}-\mathrm{c}+0.1032 \times \mathrm{Op}-\mathrm{c}-0.0168 \times \mathrm{Ep}-\mathrm{c}+237.7147
\end{aligned}
$$

Once we have gotten the factors above, energy consumption can be estimated in this way.

\section{CONCLUSION}

In this study, we collected the CDD, HDD and five economical indicators' data of 2006 year. Then we calculated the non-residential building energy consumption in 2006 year. We still made the mathematical models to understand the relation of energy consumption and these factors. $\left(\varepsilon_{1}, \varepsilon_{2}, \varepsilon_{2}, \varepsilon_{4}, \kappa_{H}\right.$, $\left.\kappa_{\mathrm{C}, \mathrm{HDD}}, \mathrm{CDD}\right) \mathrm{A}$ series of formulas like the example above are obtained. The factors can be predicted by their potential trends separately. So by using the formulas we can not only estimate the energy 
consumption now, but also the energy consumption in future. However, this is the first step of our research. It is hoped that the further surveys and research on energy consumption of China can be done to promote our research result.

\section{ACKNOWLEDGEMENT}

This study is supported by the science research expense in 2008 year (B204020104 and representative is Weijun Gao) and expense of Global environment research synthesis promotion problem of Ministry of the Environment of Japan (Hc-809 and representative is Yutaka Tonooka).

\section{REFERENCES}

Chen, S., 2008. A statistical method to investigate national energy consumption in the residential building sector of China. Energy Build., 40: 654-665. DOI: $10.1016 /$ j.enbuild.2007.04.022

Centre for Energy Saving Studies of Tsinghua University, 2008. Annual Development Report of Building Energy Efficiency in China. 1st Edn., China Architectural Industry Press, China, ISBN: 7112093465.

National Bureau of Statistics of China, 1998. China Statistics Yearbook. http://www.stats.gov.cn/tjsj/ndsj/
National Bureau of Statistics of China, 2008. China Statistics Yearbook. China Statistics Industry Press, ISBN: 978-7-5037-5530-9.

Tonooka, Y., 2008. Present Situation in China Energy and Environment in Rural Housing. Architectural Institute of Japan, Japan, ISBN: 978-4-37366-5.

Tonooka, Y., Y. Ning, A. Kannari, K. Murano and H. Higashino et al., 2004. Air pollutants and GHGs emission inventory in East Asia. Proceeding of the 13th World Clean Air and Environmental Protection Congress, Aug. 22-27, London, UK.

Tonooka, Y., J. Liu, Y. Kondou, Y. Ning and O. Fukasawa, 2006. A Survey on the Energy Consumption in Rural households in the Fringes of Xian City. Energy Build., 38: 1335-1342. DOI: 10.1016/j.enbuild.2006.04.011

Zhao, J., 2009. The analysis of energy consumption of a commercial building in TianJin, China. Energy Policy, 37: 2092-2097. DOI: 10.1016/j.enpol.2008.11.043

Zhou, N., 2008. The reality and future scenarios of commercial building energy consumption in China. Energy Build., 40: 2121-2127. DOI: 10.1016/J.enbuild.2008.06.009 